\title{
Silver (Ag) Transport Mechanisms in TRISO Coated Particles: A Critical Review
}

\section{HTR 2012}

I. J. van Rooyen

M. L. Dunzik-Gougar

P. M. van Rooyen

The INL is a

U.S. Department of Energy

National Laboratory

operated by

Battelle Energy Alliance

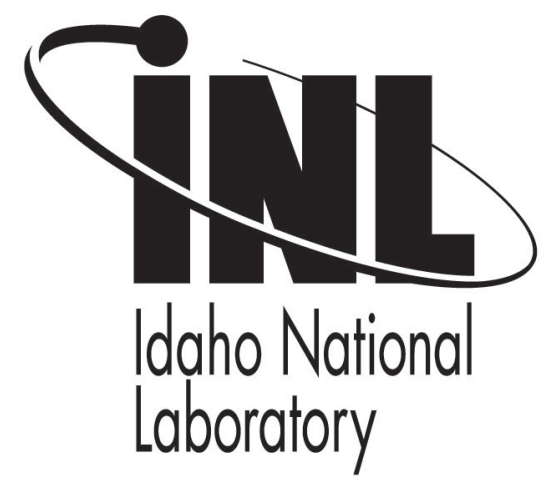

This is a preprint of a paper intended for publication in a journal or proceedings. Since changes may be made before publication, this preprint should not be cited or reproduced without permission of the author. This document was prepared as an account of work sponsored by an agency of the United States Government. Neither the United States Government nor any agency thereof, or any of their employees, makes any warranty, expressed or implied, or assumes any legal liability or responsibility for any third party's use, or the results of such use, of any information, apparatus, product or process disclosed in this report, or represents that its use by such third party would not infringe privately owned rights. The views expressed in this paper are not necessarily those of the United States Government or the sponsoring agency. 


\title{
Silver (Ag) Transport Mechanisms in TRISO Coated Particles: A Critical Review
}

\author{
IJ van Rooyen, ML Dunzik-Gougar ${ }^{1}$, PMvan Rooyen ${ }^{2}$ \\ Idaho National Laboratory \\ Idaho Falls, ID 83415-6188, USA \\ phone: +12085337199, isabella.vanrooyen@inl.gov \\ ${ }^{I}$ Department of Nuclear Engineering, Idaho State University, Idaho, USA \\ ${ }^{2}$ Philip Mvan Rooyen Network Consultants, Midlands Estates, South Africa
}

\begin{abstract}
Transport of ${ }^{110 m} \mathrm{Ag}$ in the intact SiC layer of TRISO coated particles has been studied for approximately $30 y$ ears without arriving at as atisfactory explanation of the transport mechanism. In this paper the possible mechanisms postulated in previous experimental studies, both in-reactor and out-of reactor research environment studies are critically reviewed and of particular interest are relevance to very high temperature gas reactor operating and accident conditions. Among the factors thought to influence Ag transport are grain boundary stoichiometry, SiC grain size and shape, the presence of free silicon, nano-cracks, thermal decomposition, palladium attack, transmutation products, layer thinning and coated particle shape. Additionally new insight to nature and location of fission products has been gained via recent post irradiation electron microscopy examination of TRISO coated particles from the DOE's fuel development program. The combined effect of critical review and new analyses indicates a direction for investigating possible the Ag transport mechanism including the confidence level with which these mechanisms may be experimentally verified.
\end{abstract}

\section{INTRODUCTION}

The mechanism of ${ }^{110 \mathrm{~m}} \mathrm{Ag}$ transport in the intact SiC layer of TRISO coated particles (CP) has been studied for approximately 30 years without arriving at a satisfactorily explanation for silver transport in intact coated particles.

During irradiation, the pressure inside coating layers of intact coated particles increases due to the formation of gaseous fission products and the formation of carbon monoxide from interaction between carbon material in coated particles and free oxygen released from the uranium oxide kernel during fission. This increase in pressure causes stress in the $\mathrm{SiC}$ layer, which is the main load-bearing layer in a co ated particle. Simultaneously, the PyC layers shrink due to neutron exposure offsetting the tensile stress due to gas pressure. In addition, the tensile strength of the $\mathrm{SiC}$ layer decreases due to irradiation effects. It is accepted that the $\mathrm{SiC}$ layer in a coated particle will fail when the tensile stress in the layer exceeds its tensile strength. As $\mathrm{SiC}$ is a brittle material, its failure characteristics are described by Weibull statistics. This means that a small number of $\mathrm{SiC}$ layer failures could occur during normal operation and accident conditions, due to a statistical spread in the layer strengths of individual coated particles. Therefore the design criteria are usually established to minimize each of the following phenomena to obtain optimum fuel performance:

- Fission product diffusion through intact coating layers

- CP pressure vessel failure

- $\quad \mathrm{SiC}$ layer degradation

- SiC layer thermal decomposition

The purposes of this paper are (1) to critically review previous research work conducted to establish a plausible hypothesis for the ${ }^{110 \mathrm{~m}} \mathrm{Ag}$ transport mechanism and (2) to analyze new data 
from post-irradiation examination of TRISO coated fuel with respect to lessons learned to date and (3) to propose possible experimentation designed to address remaining questions on silver transport mechanisms.

\section{SILVER TRANSPORT MECHANISM HYPOTHESES}

Based on critical review of the literature, it is clear the mechanism for silver transport has not yet been determined and therefore additional research is needed. Further, experimental conditions for reported research vary significantly and thus the results may not be compared directly. Very limited work has been performed with neutron irradiated TRISO coated particles with view on identifying the Ag transport mechanism. M any modeling efforts have been undertaken in the past five to ten years, but these efforts incorporate numerous assumptions that have not yet been confirmed empirically. In subsequent sections, mechanisms proposed in the literature are discussed.

\section{II.A. Grain Boundary Diffusion}

Nabielek et al. [1] indicated that Ag-110m release increases at temperatures of $1250^{\circ} \mathrm{C}$ and that release varies despite particles of the same manufacturing batch and irradiation conditions. The researchers offered two possible explanations for this behavior: (a) grain boundary diffusion and (b) voids at the grain boundaries. The researchers suggested both these mechanisms would be enhanced by neutron irradiation and influenced by the chemical composition at the grain boundaries. Small voids were observed at the grain boundaries but they were not interlinked and a fully developed pathway through the thickness of the $\mathrm{SiC}$ layer was not found. Similar grain boundary voids have been found in ongoing post irradiation examination of the AGR-1 coated particles. (The AGR-1 experiment is the first of a series of irradiation experiments planned in the Advanced Test Reactor (ATR) at Idaho National Laboratory (INL)). No correlation between the presence of fission products (Ag containing) and these cavities has been established at this preliminary stage of the AGR-1 microscopic examination [2].

Various other researchers have addressed the release of $\mathrm{Ag}$ as grain boundary diffusion phenomenon ([3, 4, 5]), but no data from representative and validated experimentation was provided to support this theory. Experimentation was either done on surrogate samples or no direct linkage to the actual presence of $\mathrm{Ag}$ could be made. Comparative studies described by Petti et al. [6] showed that the German smaller equaixed grains retained the ${ }^{110 \mathrm{~m}} \mathrm{Ag}$ better than the US columnar grains.

Previous fundamental studies on other materials further show that low $-\Sigma$ grain boundaries decrease the diffusion of species due to high coherency between atoms of the crystals. Coincidence site lattice (CSL) boundaries have the lowest boundary energies, in particular $\Sigma 3$ boundaries in FCC materials [7].

Recent work presented by Lopez-Honorato et al. [8] showed that although high angle boundaries do enhance diffusion of $\mathrm{Ag}$, it is not the only driver for the Ag transport and manufacturing anomalies can also result in different Ag transport behavior. LopezHonarato et al. [8] concluded grain boundary tortuosity is the predominant factor affecting $\mathrm{Ag}$ diffusion in $\mathrm{SiC}$ regardless of manufacturing defects in the layer. This phenomenon demonstrates the complexity in direct comparison of microstructure and transport studies.

In recent work, Kirchofer et al. [9] and Zuferak et al. [10] have measured grain boundary characteristics of $\mathrm{SiC}$, but these measurements were not made in conjunction with the study of ${ }^{110 \mathrm{~m}} \mathrm{Ag}$ release. In short, no experimental study to date has linked grain boundary characteristics with ${ }^{110 \mathrm{~m}} \mathrm{Ag}$ release from neutron irradiated TRISO coated particles. Therefore, determination of the grain boundary characteristics of the AGR TRISO-coated particle microstructures is indicated. EBSD techniques are most suited for this application. This recommendation forms the basis of the recommended experimental approach discussed in paragraph III.

\section{II.B. Small holes, Nano cracks, Nanotubes or Nanopipes}

As previously mentioned, Nabielek et al. [1] suggests voids at the $\mathrm{SiC}$ layer boundaries provides a mechanism for Ag transport through "intact" $\mathrm{SiC}$. This theory was further explored by MacClean et al. [11] via studies executed on 3C-CVD-SiC implanted with $\mathrm{Ag}$ with a cumulative dose from 2.4 to $14 \times 10^{16}$ atoms. This study concluded $\mathrm{Ag}$ atoms are immobilized in the structure and transport is a mechanical phenomenon occurring via "nano cracks." However, no such cracks were observed at the areas studied. This study gave birth to many interesting conversations amongst VHTR researchers and, as a r esult, to the theory of $\mathrm{Ag}$ transport via nanotubes. In this paper, nanotubes are generally referred to as carbon nanotubes. 
Nanotubes are usually smaller than nanopipes, which are typically formed during the CVD process (more detail on this definition can be found in [12]).

\section{Nanotubes (or carbon nanotubes)}

Because there have been suggestions that silver transport in irradiated TRISO coated particles occurs via nanotubes, Van Rooyen et al. [13] investigated how nanotubes could be introduced into $\mathrm{SiC}$.

Recent papers reported on the synthesis of carbon nanotubes/SiC composites using a microwave system [14] and a chemical vapor deposition system [15]. However, these nanotubes/SiC composites are not very useful for fission product transport research, because they consist of loose bundles that will make the introduction of fission products into the nanotubes very difficult.

The work of Kusunoki et al. [16] showed that a large area aligned carbon nanotube film was synthesized on the $\{0001\}$ surface of an $\alpha-\mathrm{SiC}$ wafer by heating the wafer for $30 \mathrm{~min}$. at $1700^{\circ} \mathrm{C}$ in a vacuum furnace. The nanotubes formed as a result of the decomposition of the $\mathrm{SiC}$ by selective desorption. The nanotubes were found to be multiwalled carbon nanotubes with good graphitization. Samples prepared in this way can be used to investigate the transport of silver in carbon nanotubes at high temperatures and pressure.

\section{Nanopipes (or $\mathrm{SiC}$ nanotubes)}

Nanopipes may occur in the hexagonal polytypes $(6 \mathrm{H}$ and $4 \mathrm{H})$ of $\mathrm{SiC}$ [17]. These defects can be described as screw dislocations along the c-axis with an empty core. It can be shown by using linear isotropic and thermodynamic arguments that for a $c$ axis dislocation in $6 \mathrm{H}-\mathrm{SiC}$ to have an empty core, it must be a 'superscrew' dislocation with a Burgers vector $b=n c$, where $n$ is an integer larger than unity and the lattice constant $c=1.5 \mathrm{~nm}$ [17]. In such a case, there will be a driving force for the atoms to diffuse away, which leaves the core empty. At high growth temperatures (above $2000^{\circ} \mathrm{C}$ for $6 \mathrm{H}-\mathrm{SiC}$ ), pure screw dislocations are mobile and will be attracted by nanopipes (or nanotubes). When the screw dislocations merge with the nanopipe, a superscrew dislocation is formed [17]. Formation of nanopipes (or nanotubes) by this mechanism is reported only for the hexagonal polytypes of SiC. If coated particles therefore contain a large number of hexagonal $\mathrm{SiC}$ polytypes, it is possible that nanopipes could be present in these hexagonal $\mathrm{SiC}$ grains.

Unpublished experimental work to grow nanotubes on pol ycrystalline $3 \mathrm{C}-\mathrm{SiC}$ and single crystalline $6 \mathrm{H}-\mathrm{SiC}$ was completed at Nelson Mandela Metropolitan University [13]. The samples were placed on a centrally dimpled graphite holder, with the polished side of the $\mathrm{SiC}$ pointing upwards and the matt side downward, with only the edges of the $\mathrm{SiC}$ in contact with the graphite holder. The graphite holder was placed in a vacuum furnace and heated under a vacuum pressure of between $10^{-5}$ and $10^{-6}$ mbar. Samples were heated at a rate of $25^{\circ} \mathrm{C}$ per second until a temperature of $1700^{\circ} \mathrm{C}$ was reached and maintained for 60 minutes and 30 minutes for the polycrystalline and single crystal samples respectively.

TEM analysis of these samples revealed line arrangements of carbon nanotubes/platelets were synthesized on the polished surfaces. These carbon nanotubes/platelets are in fact due to decomposition of $\mathrm{SiC}$ by selective desorption. The selected area diffraction (SAD) pattern obtained from the area containing the nanotubes exhibits diffraction rings as well as two strong $002 \mathrm{r}$ eflections in the form of arcs. The position of the 002 reflections indicates the presence of graphitic carbon with the [001] direction perpendicular to the [001] $\mathrm{SiC}$ direction (Figure 1). High resolution TEM may reveal whether these carbon structures consist of nanotubes or a type of turbostratic graphite. Also indicated is further work to determine any relationship between the $\mathrm{SiC}$ crystal orientations and the formation of the carbon nanotubes. It is envisaged that SEM-EBSD characterization prior to the heating experiments may be needed.

This experiment showed therefore that $\mathrm{SiC}$ nanotubes were not formed and therefore are not likely to be a contributing factor in $\mathrm{Ag}$ transport through the SiC layers. The research showed that the formation of nanotubes requires the decomposition of $\mathrm{SiC}$. If decomposition occurred, the remaining $\mathrm{SiC}$ would likely have failed by overpressure and $\mathrm{Ag}$ release would have taken place because of coated particle failure. This sort of failure is not observed in actual TRISO particles.

\section{II.C. SiC Layer Degradation}

Recent modeling work completed by Van der Merwe [18] is based on actual release results from TRISO fuel and he acknowledges that the actual transport mechanism has not been determined. He offered however a h ypothesis that coated particles fail due to $\mathrm{SiC}$ degradation as the dominant source term contributor at temperatures higher than $1700^{\circ} \mathrm{C}$. Based on this offering, $\mathrm{SiC}$ degradation is considered in this paper. $\mathrm{SiC}$ can decompose in a high temperature and oxygen rich environment or it can degrade due to chemical attack by fission and activation products. However, recent analysis of irradiated TRISO coated particles indicates that $\mathrm{SiC}$ 
degradation by palladium attack is not as significant as thought previously [2].

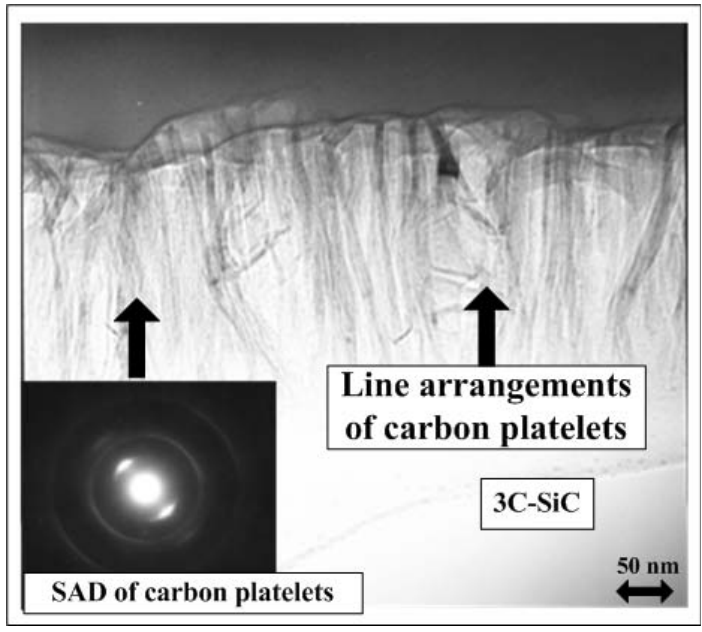

Figure 2: Bright field TEM image of nanotubes that formed on the polished side of the 3C-SiC, with a diffraction pattern of the carbon nanotubes.

It has also been found that thermal decomposition of $\mathrm{SiC}$ is primarily a function of temperature and is generally not a co ncern in reactor conditions at temperatures up to $1800^{\circ} \mathrm{C}$. However, at temperatures higher than this, it may become a concern. Very high temperature annealing studies by van Rooyen et al. [19] show that decomposition of the $\mathrm{SiC}$ layer in TRISO coated particles occurs at $1980^{\circ} \mathrm{C}$ and above. The $\mathrm{SiC}$ decomposition reaction can be expressed as:

$$
\operatorname{SiC}(s) \leftrightarrow \mathrm{Si}(g)+C(s)
$$

Silicon vapor formed in the process migrates from the $\mathrm{SiC}$ layer, leaving behind a carbon deposit. This migration leads to thinning of the $\mathrm{SiC}$ layer, thereby weakening the layer and eventually leading to its failure.

Miller et al. [20] also postulate that SiC thinning, irrespective of its nature, and subsequent directed internal pressure overload on the $\mathrm{SiC}$ layer can increase the probability of $\mathrm{SiC}$ layer failure.

$\mathrm{SiC}$ thinning and degradation is not considered a viable mechanism to describe Ag transport at reactor operating temperatures.

\section{II.D. Palladium Attack}

Neethling et al. [21] showed that Ag transport in $\mathrm{SiC}$ took place when present at the $\mathrm{SiC}$ surface as a Ag-Pd mixture. No $\mathrm{SiC}$ layer penetrations were found in the absence of Pd. Results of this study indicate $\mathrm{Pd}$ reacts with $\mathrm{Si}$ to form $\mathrm{Pd}_{2} \mathrm{Si}$ and graphite regions form due to the carbon remaining (re- precipitated) after the formation of the silicides. The researchers argue that this finding corresponds to the hypothesis that free $\mathrm{Si}$ plays a r ole in the $\mathrm{Ag}$ transport mechanism [1, 3, and 22].

Significant corrosion was observed on the $\mathrm{SiC}$ $\mathrm{Pd}-\mathrm{Ag}$ mixture interface. Interestingly, corrosion also was found on both single- and polycrystalline $\mathrm{SiC}$ surfaces. The Pd-Ag mixture penetrated the polycrystalline material alongside the grain boundaries. Significant is the finding that the leading edge of the moving material contains only $\mathrm{Ag}$ and no $\mathrm{Pd}$. Electron microscopic examination revealed that the $\mathrm{SiC}$ material behind this moving leading front appears to be intact, that $\mathrm{SiC}$ recrystalized at the tail end of this moving front. This finding is in agreement with earlier findings of Pearson et al. [23] and Lauf et al. [22]. The big disadvantage of this study is that the concentrations of $\mathrm{Ag}$ are a factor of 100 larger than those expected in an actual TRISOcoated fuel particle.

Barrachin et al. [24] confirm studies by Minato et al. [25] that show palladium is specifically present in the inner pyrocarbon layer near the inside of the $\mathrm{SiC}$ layer where it is known for attacking silicon carbide. However, no theory is offered to explain the mechanism of Ag transport to this location.

Experimental work by Demkowicz et al. [26] using a $\mathrm{SiC}-\mathrm{Pd}$ diffusion couple annealed at 1000 ${ }^{\circ} \mathrm{C}$ for $10 \mathrm{~h}$ showed the $\mathrm{SiC}-\mathrm{Pd}$ reaction extended through the entire $250 \mu \mathrm{m} \mathrm{Pd}$ foil. This work suggests that $\mathrm{SiPd}_{2}$ and $\mathrm{SiPd}_{2}+\mathrm{C}$ regions are found in the reaction zones. These diffusion conditions are not representative of the conditions in the actual coated particle although the suggested compounds may be useful in interpretation of compounds found in the actual irradiated $\mathrm{SiC}$ layer. However, as mentioned earlier, SiC degradation by palladium attack is not as significant as expected as shown by recent AGR-1 PIE results [2].

II.E. Radiation -Induced Point Defects, Displacement Energies and Diffusion Coefficients

Radiation-induced changes in $\mathrm{SiC}$ are also important when $\mathrm{Ag}$ transport is evaluated as the micro- and nanostructure of $\mathrm{SiC}$ changes during irradiation. In previous paragraphs, it is speculated that $\mathrm{Ag}$ transport is influenced by voids or cavities, which form in the $\mathrm{SiC}$ structure. During neutron irradiation, significant gas production, transmutation and microstructural changes for $\mathrm{SiC}$ will take place ([27, 28, and 29]. During ion implantation, or neutron irradiation, point defects (interstitial atoms and vacancies) and cavities are simultaneously generated in the specimen. In the case of ion implantation, the specimen will also contain the 
implanted ions, whereas in the case of neutron irradiation, knock-on (scattered) atoms and atoms produced by nuclear transmutation will be present in the specimen. In the case of $\mathrm{SiC}$, the interstitial atoms and vacancies are from both sub-lattices, i.e. silicon and carbon. Point defects produced by irradiation (or implantation) can be trapped by a number of sinks of which the following are the most important:

- Interstitial and vacancy recombination will result in mutual annihilation.

- In the case of hydrogen or helium implantation, some vacancies may trap hydrogen/helium atoms, leading to the formation of gas-filled bubbles or two-dimensional platelets.

- Interstitials or vacancies can be trapped by dislocations, dislocation loops and voids.

For dislocation loops to nucleate and grow, it is required that both silicon and carbon interstitial atoms be present at the loop nucleation site [30 Vladimirov et al. [31] gives displacement energies $\left(E_{d}\right)=93 \mathrm{eV}$ for silicon and $16 \mathrm{eV}$ for carbon. Based on these displacement energy values, about five times more carbon than silicon interstitials are produced during irradiation. In order for displaced atoms to interact during post-irradiation annealing, they must be mobile enough to migrate to the various sinks. A carbon interstitial is more mobile than the silicon interstitial. It is deduced from the diffusion coefficients reported by Salvador et al. [32] that silicon and carbon interstitials are mobile enough at $1000 \mathrm{~K}$ for the nucleation and growth of dislocation loops.

Price [33] reported that $3 \mathrm{C}-\mathrm{SiC}$ irradiated at $900^{\circ} \mathrm{C}$ at a fluence of $2.4 \times 10^{21} \mathrm{ncm}^{-2}$ $(\mathrm{E}>0.18 \mathrm{MeV}$ ) contained small Frank loops (with mean diameter of $3.5 \mathrm{~nm}$ ) on $\{111\}$ planes. After annealing the irradiated samples at $1500^{\circ} \mathrm{C}$ for one hour, the mean loop diameter increased by $0.6 \mathrm{~nm}$ with a few large loops having diameters of $10 \mathrm{~nm}$. Samples irradiated at 1250 and $1500^{\circ} \mathrm{C}$ contained a high density of voids uniformly distributed through the TEM foils. In $\mathrm{SiC}$ samples irradiated at $1250^{\circ} \mathrm{C}$ at a fluence of $4.3 \times 10^{21} \mathrm{ncm}^{-2}(\mathrm{E}>0.18 \mathrm{MeV})$ followed by a $1 \mathrm{~h}$ our anneal at 1800, 1900 and $2000^{\circ} \mathrm{C}$, the void densities decreased and the maximum void diameters increased, reaching 30 to $40 \mathrm{~nm}$. It is suggested that the high density of voids present in the unannealed neutron-irradiated $\mathrm{SiC}$ samples could form void channels that could provide pathways for fission product release. This has not been proven yet but is considered during ongoing AGR-1 post irradiation examination.
Yano et al. [34] used HRTEM to investigate 3C$\mathrm{SiC}$ irradiated at temperatures between 370 and $650^{\circ} \mathrm{C}$ at a fluence of $1.9 \times 10^{23} \mathrm{ncm}^{-2}$. The first evidence of neutron radiation damage in the form of interstitial dislocation loops on $\{111\}$ planes appeared for a fluence of $4.8 \times 10^{22} \mathrm{ncm}^{-2}$ at an irradiation temperature of about $500^{\circ} \mathrm{C}$. This finding is consistent with the earlier observations of Price [33]. Furthermore, the use of HRTEM by Yano et al. [34] revealed that the Frank loops produced by neutron irradiation in $3 \mathrm{C}-\mathrm{SiC}$ are extrinsic in nature. No voids were observed even for the fluence of $1.9 \times 10^{23} \mathrm{ncm}^{-2}$. The critical temperature for vacancy migration is suggested to be above $1200^{\circ} \mathrm{C}$ and that for void formation $1400^{\circ} \mathrm{C}$. However, it needs to be considered that this experimental work was done at very high neutron (50 to 200 times) dose compared to the design dose for VHTR.

\section{II.F. Transmutation Products}

Transmutation products, in particular phosphorous, are identified by Van Rooyen et al. [41] as factors in $\mathrm{Ag}$ transport as transmutation products may influence the micro- and nanostructures of the $\mathrm{SiC}$ layer, as well as possibly the chemical reactivity.

Heinisch et al. [29] calculated the following concentrations of elements resulting from neutron irradiation of pure $\mathrm{SiC}$ in a HTGR after 10 full power years (4.4 dpa): phosphorus (36 appm), hydrogen ( $8 \mathrm{appm})$, helium (5.8 appm) and lower concentrations of magnesium and beryllium.

Natural silicon occurs as three stable isotopes, namely ${ }^{28} \mathrm{Si},{ }^{29} \mathrm{Si}$ and ${ }^{30} \mathrm{Si}$, of which the latter occurs on average as every $33 \mathrm{rd}$ atom. ${ }^{30} \mathrm{Si}$ transmutes to phosphorus $\left({ }^{31} \mathrm{P}\right)$ during neutron irradiation, acquiring a neutron to form ${ }^{31} \mathrm{Si}$, which then decays to ${ }^{31} \mathrm{P}$ by beta-emission. This amounts to 8.2 appm/dpa phosphorus which may affect the integrity of the $\mathrm{SiC}$ layer and is therefore considered in this study for potential contributing to the $\mathrm{Ag}$ transport mechanism thought the $\mathrm{SiC}$ layer.

Nuclear transmutation doping $([28,35])$ is based on the reaction:

Heissenstein and Helbig [28] found that a 30minute anneal at $1700^{\circ} \mathrm{C}$ activated $82 \%$ of the phosphorus produced by neutron transmutation (thermal neutron fluence of $8.3 \times 10^{19} \mathrm{ncm}^{-2}$ and fast neutron fluence of $2 \times 10^{18} \mathrm{ncm}^{-2}$ ). These findings are in agreement with Young et al., [36] who found that up to a fast neutron fluence of $10^{20} \mathrm{ncm}^{-2}$ radiation damage can be removed by annealing for 
$30 \mathrm{~min}$. at $750^{\circ} \mathrm{C}$, except for a r esidual minoritycarrier recombination effect.

Baranov et al. [37] established that the phosphorus at the carbon position is unstable and annealing above $1700^{\circ} \mathrm{C}$ causes phosphorus at the carbon site to move to the silicon site. This process is vacancymediated, as the temperature of this process is shown to depend on the thermal stability of neutroninduced defects, of which the concentration is proportional to the neutron irradiation dose.

Bockstedte et al. [38] theoretically investigated the solubility of phosphorus in $4 \mathrm{H}-\mathrm{SiC}$ and made the following statement: phosphorus preferentially substitutes for silicon (PSi) rather than for carbon (PC). Phosphorus pairs and complexes with vacancies and antisites occur in much lower concentration than PSi. The solubility of phosphorus in carbon-rich $4 \mathrm{H}-\mathrm{SiC}$ at $1427^{\circ} \mathrm{C}$ is $6 \times 10^{18} \mathrm{~cm}^{-3}$. This phosphorus concentration is also on the same order found by neutron-transmutation studies done by Baranov et al. [37] for a neutron dose of $\sim 1 \times 10^{20} \mathrm{ncm}^{-2}$ for ${ }^{30} \mathrm{Si}$ enriched SiC. Wellmann [39] found that P-doping concentrations of up to $1.3 \times 10^{18} \mathrm{at} / \mathrm{cm}^{3}$ were achieved and further suggested that much higher doping levels are achievable.

Malherbe et al. [40] reported on the effect of the introduction of phosphorus atoms to the SiC lattice. Simulations were performed, subjecting a small 92atom $\mathrm{SiC}$ cluster to a nuclear reaction with a neutron in which one of the silicon atoms is converted into a phosphorus atom. Two structural states of the lattice are possible (Figure 2) at the time when the conversion is concluded, namely:

- The silicon atom is converted to a neutral trigonal pyramidal phosphorus atom (structurally equivalent to the gaseous compound $\mathrm{PH}_{3}$ ), from which three covalent bonds emanate to bond to the nearest carbon atoms. This path leaves one dangling bond hanging from the fourth carbon atom surrounding the phosphorus atom. The results are structural instability from the defect bonding situation, and chemical instability from the unpaired spin on the carbon atom, especially if the phosphorus atom is near or at the surface of the cluster.

- The silicon atom is converted into a $\mathrm{P}^{+}$ion from which four equivalent tetrahedral bonds emanate to bond with the four nearest carbon atoms. This should lead to large changes in the charges of the atoms nearest to the phosphorous ion, as well as to structural effects. The effect of the charges may be more serious that than of the structure, because it is not expected that the P-C distances (normally around $1.85 \AA$ ) in the cluster would be much different from the Si-C distances.

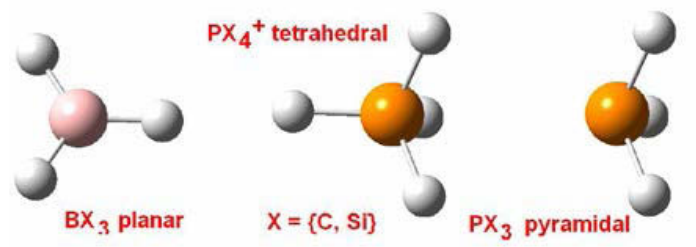

Figure 2: The three types of $\mathrm{P}$ and $\mathrm{B}$ structures, which might perturb the $\mathrm{SiC}$ lattice when introduced on Si-sites in the SiC lattice [40].

Malherbe et al. [40] found that the conversion of some or even all of the ${ }^{30} \mathrm{Si}$ to ${ }^{31} \mathrm{P}$ in the $\mathrm{SiC}$ lattice does not lead to exceptional lattice strain. $\mathrm{T}$ his phenomenon was explained by the small difference $(\sim 0.07 \AA$ ) between the $\mathrm{Si}-\mathrm{C}$ and the $\mathrm{P}+-\mathrm{C}$ bond lengths and the tetrahedral bonding (Figure 3 ). The conversion of the ${ }^{30} \mathrm{Si}$ to ${ }^{31} \mathrm{P}$ in the $\mathrm{SiC}$ lattice does have an impact on the electron distribution in the lattice, opening up the possibility of chemical and physical attack upon the usually stable lattice. This may be of particular interest in light of the recent findings by Neethling et al. [21] that the silver transport mechanism may be linked to the palladium-silver interaction with the $\mathrm{SiC}$ layer. It is suggested that the chemical attack by palladium may be enhanced. This notion still needs to be verified.

In experimental work by Van Rooyen et al. [41], no significant influence of P-doping could be detected on the structural properties of un-irradiated material and no new insight was gained with respect to the effect of transmutation products on the $\mathrm{Ag}$ transport mechanism. It should be noted that only unirradiated material was considered in this study and no actual Ag transport studies were conducted. While a single factor does not appear to influence a process when considered in isolation, there may be several factors working symbiotically to effect a change. For example, Ag transport through $\mathrm{SiC}$ may be significantly affected by $\mathrm{P}$ reactivity combined with irradiation damage or voids creation. Results of this work indicate $P$ profile measurements over grain boundaries rather than bulk $\mathrm{P}$ analysis. It is suggested that $\mathrm{P}$ can agglomerate at the grain boundaries, thereby causing a higher reactivity in that region and assisting grain boundary diffusion. 


\section{FISSION PRODUCT IDENTIFICATION IN INL AGR-1 EXPERIMENT}

Detailed electron microscopic examination was completed on two fuel compacts of AGR-1 experiment at INL and results are described in paper HTR2012-3-023 [2]. The Ag-110m release data indicate that the average fraction of silver release in each capsule ranged from $1.2 \times 10^{-2}$ to $3.8 \times 10^{-1}$ [42] .

The electron microscopy examination showed that the fission product precipitates are found at the IPyC-SiC interface in both the IPyC and SiC layers. Significantly, palladium rich precipitates were found mainly at the $\mathrm{SiC}$ grain boundaries with a crystal structure similar to $\mathrm{UPd}_{2} \mathrm{Si}_{2}$, but proportions of $\mathrm{U}$, $\mathrm{Pd}$, Si may vary. This structure is only reported for the $\mathrm{Pd}$-rich precipitates found in the $\mathrm{SiC}$ layer and is not relevant for Pd found outside the coated particle where no $U$ was found. Interestingly, fission product precipitates could only be seen up to a d epth of approximately $17 \mu \mathrm{m}$.

Results of EDS analyses were inconclusive (EDS peak overlaps and concentration ratio differences) with regard to the presence of Ag. Preliminary diffraction patterns show similar crystallographic direction at same orientation relative to the TEM sample. No significant differences were found in $\mathrm{SiC}$ microstructure between the high and low silver releasing particles. Upcoming analyses of grain size and texture morphology may reveal differences between the particles.

Grain boundary character parameters were examined to determine if there were significant differences among the particles. Two types of AGR1 compacts namely the baseline fuel (B) and fuel variant 3 (V3) were examined by Van Rooyen et al. [2]. The baseline fuel was fabricated with coating process conditions similar to those used to fabricate historic German fuel because of its excellent irradiation performance with $\mathrm{UO}_{2}$ kernels. The AGR-1 fuel is, however, made of low-enriched UCO (uranium oxycarbide). The variant 3 fuel carrier gas composition for the $\mathrm{SiC}$ layer deposition was changed from $100 \%$ hydrogen to a $50 \%$ argon- $50 \%$ hydrogen mixture and the deposition temperature was lowered relative to the baseline (from 1500 to $\left.1425^{\circ} \mathrm{C}\right)$. Demkowicz et al. [42] suggest that significant silver was released from the Baseline particles (compact 6-3-2) as compared to the Variant 3 particles (compact 4-1-1) at similar temperatures.

The grain size for Variant 3 is a fairly constant $0.75 \mu \mathrm{m}$ throughout the thickness of the $\mathrm{SiC}$ layer. In contrast, grain size in the Baseline fuel $\mathrm{SiC}$ layer varies from 1.9 to $2.3 \mu \mathrm{m}$ as found in earlier studies of unirradiated TRISO coated particles by Kirchofer et al. [9]. This difference suggests the presence of Pd-rich precipitates is not a function of grain size but rather other microstructural parameters are important. However, when comparing the grain boundary characteristics (Table 1), it was found that there are no significant differences between the Baseline and Variant 3 fuels. When the high angle boundaries are considered (Table 1), the Variant 3 (compact 4-1-1) could have a ${ }^{110 \mathrm{~m}}$ Ag release similar to, or even higher than, the Baseline particles $(0.39$ if compared to the 0.36 boundary fraction). Instead, the particle with the higher fraction of high angle grain boundaries did not release any silver and that with the lower boundary fraction released about half of its silver. These data contrast with the prevalent theory that release fractions vary directly with the concentration of high angle grain boundaries and thereby exemplify the importance of obtaining EBSD measurements on the actual coated particle where the release fraction was specifically determined. This type of analysis is planned as part of the AGR-1 PIE campaign [2].

Yet to be determined via electron microscopic examination is the tortuosity of the grain boundaries and relative differences between the fuel types. This analysis is planned. It is important to note that no Pd corrosion attack was observed on these samples. This observation is in contrast with the hypothesis of Neethling et al. [21] and with the phenomenon observed on actual irradiated coated particles as reported by Minato et al. [25].

Table 1: Grain boundary characteristics of unirradiated coated particles of the AGR-1 experiment (Adapted from [9]).

\begin{tabular}{|c|c|c|c|}
\hline \multirow{2}{*}{ Description } & \multirow{2}{*}{ Parameter } & \multicolumn{2}{|c|}{$\begin{array}{c}\text { Boundary } \\
\text { Fraction } \\
\end{array}$} \\
\hline & & $\mathrm{B}$ & V3 \\
\hline \multirow{3}{*}{$\begin{array}{l}\text { Grain Boundary } \\
\text { Character } \\
\text { Distribution }\end{array}$} & $\begin{array}{l}\text { Low Angle } \\
\left(2^{\circ} \leq \text { Angle }<15^{\circ}\right)\end{array}$ & 0.24 & 0.21 \\
\hline & $\begin{array}{l}\mathrm{CSL}^{*} \\
(\Sigma 3-\Sigma 29)\end{array}$ & 0.40 & 0.40 \\
\hline & $\begin{array}{l}\text { High Angle } \\
\left(\text { Angle }>15^{\circ}\right)\end{array}$ & 0.36 & 0.39 \\
\hline \multirow{6}{*}{$\begin{array}{l}\text { CSL* Boundary } \\
\text { Distribution }\end{array}$} & $\Sigma 1$ & 0.24 & 0.21 \\
\hline & $\Sigma 3$ & 0.29 & 0.27 \\
\hline & $\Sigma 9$ & 0.04 & 0.05 \\
\hline & $\Sigma 27$ & 0.01 & 0.01 \\
\hline & Other $\Sigma$ & 0.42 & 0.46 \\
\hline & $\begin{array}{l}\text { Measured/calculated } \\
\text { Ag-110m ratio [39] }\end{array}$ & 0.51 & 1.03 \\
\hline
\end{tabular}

*Coincidence Site Lattice Theory 


\section{SILVER TRANSPORT MODELLING APPROACHES}

It is not the aim of this paper to do a comprehensive review of transport modeling approaches. Rather, attention is given to the need for, and lack of, $\mathrm{Ag}$ transport modeling that is adequately substantiated by experimental mechanistic studies.

One example of recent modeling work is by Van der Merwe [18]. A diffusion-based, computational model was developed for a temperature range from 800 to $1700^{\circ} \mathrm{C}$. Van der Merwe [18] described the model as being based on empirical release data and as not incorporating a specific transport mechanism. The model assumed coated particle failure due to $\mathrm{SiC}$ degradation as the dominant source term contributor for temperatures higher than $1700^{\circ} \mathrm{C}$. This assumption is inconsistent with results from various researchers indicating $\mathrm{SiC}$ decomposition takes place only above $2000^{\circ} \mathrm{C}$. Furthermore, $\mathrm{SiC}$ degradation by palladium attack is also not as significant as expected as shown by recent AGR-1 PIE results [2].

In other recent work, Xiao et al. [43] have evaluated the adsorption and diffusion of $\mathrm{Ag}$ on mainly (001) 3C-SiC surfaces. The (001) surfaces are relatively more open to impurity adsorption as planar atom density is lower than the other planar surfaces. It was found that the mobility of $\mathrm{Ag}$ is high on the surface and Ag prefers to adsorb on the surface and not in bulk. The researchers suggested surface diffusion as a mechanism for $\mathrm{Ag}$ transport from the $\mathrm{SiC}$ layer into the reactor environment; however, results of the data analyses do not indicate a mechanism only that $\mathrm{Ag}$ prefers not to be in the bulk material.

\section{EXPERIMENTATION APPROACH}

Review of previous Ag transport research highlighted the following shortfalls in experimental studies to date.

- Limited mechanistic studies have been performed using actual TRISO coated particles

- Silver concentrations in many laboratory experiments are orders of magnitude larger than expected based on the neutron spectrum in a typical VHTR. Higher Ag concentrations may introduce a co ncentration effect on diffusion and therefore mechanistic results may not be representative of those in the real system
- Silver quantities in actual TRISO-coated particles are not readily detected with SEM-EDS, SEM-WDS and TEM-EDS due to low concentrations. Availability of more sensitive instrumentation for radioactive samples is limited

- Often experimental work is done on different polytypic structures of $\mathrm{SiC}$

- Crystal orientations are not characterized

- The impact of surface effects (e.g. roughness) is not considered

- Implantation of Ag ions results in Ag location in lattice positions not representative of the neutroninduced fission system; also, radiation damage to the materials is inadequately simulated

- The effect of transmutation products has not been considered fully

- Dislocation and irradiation cavity concentrations are not measured (quantified) in relation to the fission product concentrations found in the $\mathrm{SiC}$

- Grain boundary diffusion has not been characterized as a function of grain size and shape in actual irradiated coated particles with fission product precipitates present

- The effect of solid solubility of Ag and other fission products is not considered fully

- The actual VHTR conditions are not simulated accurately in the experimental studies or all of the criteria are not simultaneously met, namely:

- Spherical geometry of coating layers

- Internal pressure on layer

- CO concentrations

- Temperature gradient

- Fission product concentrations

- SiC CVD coating properties (coating deposition conditions may have an impact on the grain boundary characteristics)

- Neutron irradiation (out-of pile experimentation is often done with proton irradiation)

From the significant experimentation done over the past 30 years and the recent AGR-1 PIE results, it may be considered that the Ag transport mechanism cannot be attributed to a single factor, but rather to the combined effect of more than one factor. To this end, either the experiments should be designed to simulate the expected environment or detailed PIE examinations should be conducted with more sensitive techniques on actual irradiated coated particles.

Although such work is not planned, the AGR-1 irradiated TRISO particles represent a tremendous opportunity to perform some of the multi-factor analyses needed to reveal the mechanism of $\mathrm{Ag}$ 
migration. B ased on the literature reviewed, AGR-1 PIE conducted to date, and the availability of previously characterized TRISO particles, an experimental approach is proposed in this paper. The three proposed experiments comprise a combined parametric study and two separate effects experimental approaches. It is expected that transport model development take place in parallel with the experimental work. W ith the availability of experimental data, development of fission product release and fuel performance models should be coordinated with transport modeling.

\section{V.A. Ag Transport Mechanism Experimental Study 1}

Experiment 1 is focused on analysis of particles from the AGR-1 irradiation, which provides the opportunity to examine real fission product precipitates under the actual post-irradiation conditions. The greatest challenges to overcome to do this research are the availability of the advanced technique analyses instruments in a controlled environment for irradiated materials.

This research plan addresses the following shortfalls (mentioned above):

- Characterization of grain boundary characteristics in the area of the precipitates. Data from this type of analysis will provide details, for example of the high angle grain boundary distribution, to test recent grain boundary-Ag transport mechanism hypothesis by researchers $[8,9$, and 10$]$. In addition these data will allow for validation of Xiao et al.'s [43] finding on $\mathrm{t}$ he specific adsorption properties of the (001) surface of $3 \mathrm{C}-\mathrm{SiC}$.

- Measurement of the actual P profile over the grain boundary could provide information about factors contributing to $\mathrm{P}$ reactivity towards $\mathrm{Ag}$ and other fission products. The confirmation of $P$ concentrations at the grain boundaries will test the recent hypothesis by van Rooyen et al. [41].

- Measurement of actual grain and precipitate orientations.

- Determination of composition gradients across the $\mathrm{SiC}$ thickness to validate (or invalidate) hypotheses like those of Neethling et al. [35].

- Characterization with production of repeatable, representative and comparable data. Four positions in one coated particle will be analyzed and the results compared. Additionally, the study will evaluate the representativeness among particles of a batch.

- All other shortcomings are addressed, as it is irradiated coated particles to be characterized.
Figure 3 shows a schematic plan of the proposed research identifying the risk areas for the successful completion of this research plan. The availability of the relevant advanced techniques for transuranic irradiated material is the main perceived risk, as these advanced techniques are generally in areas not licensed to work with irradiated transuranic material. This risk can be overcome, but it may have a time penalty to the expected outcome.

\begin{tabular}{|l|l|}
\hline \multicolumn{1}{|c|}{ Ag transport mechanism experiment 1 } \\
\hline AGR-1 Compact 6-3-2 & \multicolumn{1}{|c|}{ AGR-1 Compact 4-1-1 } \\
\hline \begin{tabular}{|l|}
\hline Average Ag retained (3 \\
CPs)
\end{tabular} \\
\hline 1 CP) (3 CPs) \& low Ag retained
\end{tabular}

Figure 3: Ag transport mechanisms experimental research plan 1 .

V.B. Ag Transport Mechanism Experimental Study 2

The aim of the second proposed study is to execute controlled experiments representative of actual coated particles but with a h igher $\mathrm{Ag}$ concentration to overcome the problem of measurement sensitivity.

Experiments will be performed with unirradiated materials to determine separately the effects of $\mathrm{Ag}$ and Pd. Results from these tests will be compared with those from irradiated experimental coated particles, which include the effects of transmutation products and neutron irradiation.

This research plan (Figure 4) is very ambitious because it includes the development of a simulated coated particle with $\mathrm{Ag}$ and Ag-Pd mixtures within the kernel. This simulated coated particle will allow the chemical species to react in a similar manner to the expected conditions. More representative information is anticipated because $\mathrm{Ag}$ would be measured with SEM-EDS and SEM-WDS techniques. 
This experimental plan addresses many shortfalls identified in some of the previous research, because final measurements will be of an irradiated, spherical CP. The only deviation from expected conditions is Ag spiking of the kernels prior to irradiation and annealing. This deviation allows for accurate detection of Ag with the current INL TEMEDS and prevents additional complications of transferring samples to another facility and licensing other facilities.

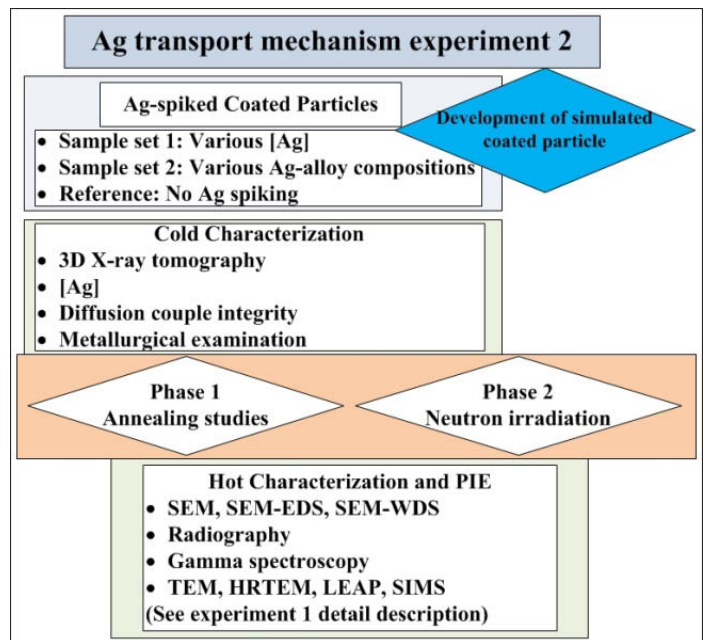

Figure 4: Ag transport mechanisms experimental research plan 2 .

\section{V.C. Ag Transport Mechanism Experimental Study 3}

The objective of the third proposed research plan is to determine the effect of $\mathrm{P}$ distribution and reactivity on the $\mathrm{Ag}$ transport mechanism and transport rate. This experimental work (diagramed in Figure 5) is designed to explore the effect of transmutation products on $\mathrm{t}$ he $\mathrm{Ag}$ transport mechanisms. The effect of $\mathrm{P}$ as the transmutation product will be studies in the absence of irradiation damage to the structure. Thus, only the chemical bonding aspects will be considered. This isolated factor has been addressed only in a limited manner in previous studies and the proposed plan brings together the specific alloy composition of the precipitates as produced during the AGR1 experiment.

As mentioned earlier, previous work by Van Rooyen et al. [41] was only conducted on unirradiated $\mathrm{SiC}$ and only a structural evaluation was completed. Recommendations and caution from this work provide the opportunity for further exploration related to Ag-mixture transport experimentation on P-doped samples. This proposed Ag-mixture transport experimentation will provide new information on the possible higher reactivity of $\mathrm{Ag}$ with an enriched $\mathrm{P}$ doped $\mathrm{SiC}$ structure. Evidence was provided earlier that chemical reactivity may be enhanced due to the P; however, this effect was previously only considered for un-irradiated material and no actual Ag transport studies were conducted. Concentration of $\mathrm{P}$ on the grain boundaries may play a role in $\mathrm{Ag}$ precipitation and/or reaction.

A second phase of this study is to include irradiation after the initial cold characterization is complete. Comparison of pre- and post-irradiation characterization data will provide valuable scientific information for performance modeling. (It should be noted that the coated particle samples are available and earlier research with them is described by Van Rooyen et al. [41]).

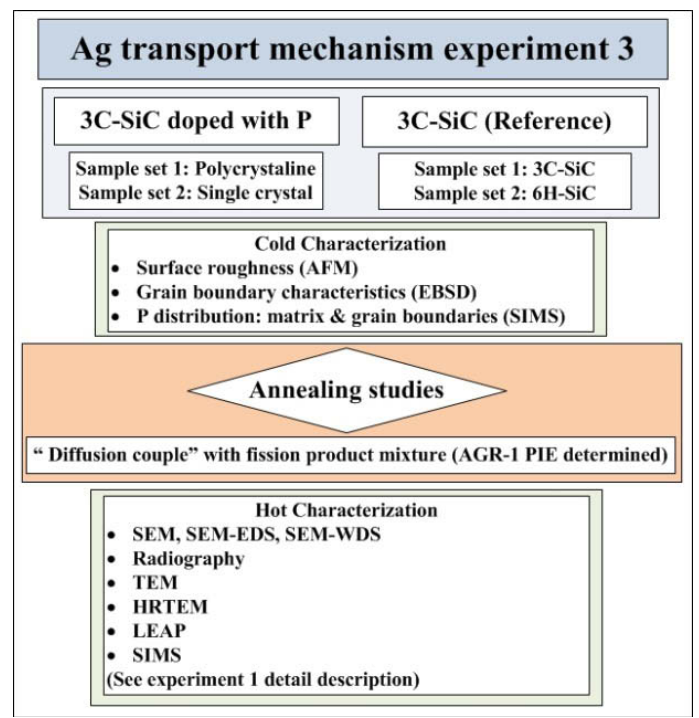

Figure 5: Ag transport mechanism experimental research plan 3 .

\section{CONCLUSIONS}

The critical review of previous research work clearly demonstrated that the mechanism for silver transport has not yet been determined and therefore additional research is needed. It also became clear that the experimental conditions varied widely and results may not be compared directly. In addition, very limited work has been performed with irradiated TRISO coated particles with focus on identifying the $\mathrm{Ag}$ transport mechanism.

This paper presented three pathways for $\mathrm{Ag}$ transport studies based on the literature reviewed, AGR-1 PIE and lessons learned from previous experimentation. It is expected transport modeling needs are considered throughout experimentation in 
order to provide data to improve fission product release and fuel performance models.

The preliminary AGR-1 PIE has already contributed significantly towards a better understanding of the actual precipitate compositions and orientation. It is therefore crucial to benefit fully from the availability of irradiated CPs to complete the proposed experimental plan 1 .

\section{ACKNOWLEDGMENTS}

This work was partially supported by the U.S. Department of Energy, Office of Nuclear Energy, under the Next Generation Nuclear Plant program. This work was also supported by the researchers in their private time.

Prof Jan Neethling (Nelson Mandela Metropolitan University) is acknowledged for his contribution towards the influence of the irradiation effects. PBMR (Motshudi Modukwe and Jan Neethling) is further acknowledged for the $\mathrm{SiC}$ decomposition micrographs.

\section{REFERENCES}

[1] H. Nabielek, P. E. Brown, The Release of Silver $-110 \mathrm{~m}$ in High Temperature Reactors: Technical Note, OECD Dragon Project. Vol. 657, 1975 p. 370

[2] I. J. van Rooyen, D. E. Janney, B. D. Miller, P. A. Demkowicz, E lectron Microscopic Evaluation and Fission Product Identification if Irradiated TRISO Coated particles from the AGR-1 Experiment: A Preliminary Review, HTR2012-3-23, Tokyo, Japan

[3] R. C. Martin, Diffusion Modelling of Fission Product Release During Depressurized Core Conduction Cooldown Conditions, Oak Ridge National Laboratory, USA1991

[4] W. Amian, D. Stöver, Diffusion of silver and cesium in silicon-carbide coatings of fuel particles for high-temperature gas-cooled reactors: Nuclear Technology Vol. 61 (1983) 475 $-486$

[5] E. Friedland, J. B. Malherbe, N. G. van der Berg, T Hlatshwayo, A. J. Botha, E. Wendler, W. Wesch, Study of silver diffusion in silicon carbide, Journal of Nuclear Materials 389 (2009) 326-331

[6] D. A. Petti, J. Buongiorno, J. T. Maki, R.R. Hobbins, G. K. Miller, Key differences in the fabrication, irradiation and high temperature accident testing of US and German TRISOcoated particle fuel, and their implications on fuel performance, Nucl. Engineering and Design, Vol. 222 (2003) $281-297$

[7] T. Fujita, Z. Horita, and T. G. Langdon, "Using Grain Boundary Engineering to Evaluate the Diffusion Characteristics in Ultrafine-Grained $\mathrm{Al}-\mathrm{Mg}$ and $\mathrm{Al}-\mathrm{Zn}$ alloys," Mater. Sci. Eng. A, 371, 241-50 (2004).

[8] E. Lopez-Honorato, D. X. Yang, J. Tan, P. J. Meadows, and P. Xiaow, Silver Diffusion in Coated Fuel Particles, J. Am. Ceram. Soc., 93 [10] 3076-3079 (2010)

[9]R. Kirchhofer, J.D. Hunn, P.A. Demkowicz, J.I. Cole, and B.P.Gorman, Microstructure of TRISO Coated Particles from the AGR-1 Experiment: $\mathrm{SiC}$ Grain Size and Grain Boundary Character. Submitted to Journal of Nuclear Materials. (July 2012)

[10]T. Gerczak, Univeristy of Wisconsin, Private conversation (March 2012)

[11]H. J. MacLean, R. G. Ballinger, L.E. Kolaya, S. A. Simonson, N. Lewis, M. E. H anson, The effect of annealing at $1500{ }^{\circ} \mathrm{C}$ on migration and release of ion implanted silver in CVD silicon carbide, J. Nucl. Mater. Vol. 357 (2006) 31 - 47

[12]K. D Sattler, Handbook of Nanophysics: Nanotubes and nanowires, (2010) Google books

[13]I. J. van Rooyen, S. M. Mokoduwe, J. H. Neethling, Unpublished data on nanotubes experimentation conducted at NMMU during 2009

[14] Y. Wang, Z. Iqbal, S. Mitra, Rapid, low temperature microwave synthesis of novel carbon nanotube-silicon carbide composite: Carbon, Vol. 44 (2006) $2804-2808$

[15] L. Ci, Z. Ruy, N. Y. Jin-Phillipp, M Rühle, Carbon nanotubes/SiC whiskers composite prepared by CVD method: Diamond and Related Materials, Vol. 16 (2007) $531-536$

[16]M. Kusunoki, J. Shibata, M. Rokkaku, T. Hirayama, Aligned Carbon Nanotube Film SelfOrganized on a S iC Wafer, Jpn. J. Appl. Phys. Vol. 37 (1998) L605 - L606

[17]P. Pirouz On micropipes and nanopipes in $\mathrm{SiC}$ and GaN: Philosophical Magazine A Vol. 78 (1998) $727-736$

[18]J. J. van der Merwe, Modelling silver transport in spherical HTR fuel. University of Pretoria $\mathrm{PhD}$ thesis (2009)

[19]IJ van Rooyen, J. H. Neethling, A. Henry, E Janzén "Influence of phosphorous and high temperature on the nanostructures of $3 \mathrm{C}-\mathrm{SiC}$ ", HTR2010 paper 164, Prague, October 2010

[20]G. K. Miller, D. A. Petti, J. T. Maki, D. L. Knudsen, An evaluation of the effects of $\mathrm{SiC}$ layer thinning on failure of TRISO-coated fuel particles, J. Nucl. Mater. 355 (2006) 150-162 
[21]J. Neethling, J. O'Connell, J. Olivier, Palladium assisted silver transport in polycrystalline $\mathrm{SiC}$, AG-PD HTR2010-196

[22]R.J. Lauf, T.B. Lindemer, R.L. Pearson, Out-ofReactor Studies of Fission Product-Silicon Carbide Interactions in HTGR Fuel Particles, Journal Nuclear Materials, 120, p. 6, 1984.

[23]R.L. Pearson, R.J. Lauf, T.B. Lindemer, The Interaction of Palladium, the Rare Earths, and Silver with Silicon Carbide in HTGR Fuel Particles, Oak Ridge National Laboratory, Oak Ridge Report ORNL/TM-8059, 1982.

[24]M. Barrachin, R. Dubourg, S. de G root, M.P. Kissane, K. Bakker, Fission-product behaviour in irradiated TRISO-coated particles: Results of the HFR-EU1bis experiment and $t$ heir interpretation . J Nucl Mater, 415 (2011) 104116

[25]K. Minato, T. Ogawa, K. Fakuda, H. Sekino, H. Miyanishi, S. Kado, I. Takahasi, Release behaviour of metallic fission products from HTGR fuel particles at 1600 to 1900 oC: J. Nucl. Mater. Vol. 202 (1993) 47 - 53

[26]P. Demkowicz, K. Wright, J. Gan, D. Petti, High temperature interface reactions of $\mathrm{TiC}, \mathrm{TiN}$, and $\mathrm{SiC}$ with palladium and rhodium, Solid State Ionics, Volume 179, Issue 39, 15 December 2008, 2313-2321

[27]L. L. Snead, R. H. Jones, A. Kohyama, P. Fenici, Status of silicon carbide composites for fusion, Journal of Nuclear Materials 233-237 (1996) 2636

[28]H. Heissenstein, R. Helbig, Characterization of SiC: $P$ prepared by Nuclear Transmutation due to Neutrons, Materials Science Forum, Vols. 353-356 (2001) 369-372

[29]H. L. Heinisch, L.R. Greenwood, W. J. Weber, R. E. Williford, Displacement damage in silicon carbide irradiated in fission reactors, Journal of Nuclear Materials, 327 (2004) 175-181

[30]A. I. Ryazanov, A. V. Klapstocv, A. Kohyama, H. Kishimoto, Radiation swelling of $\mathrm{SiC}$ under neutron irradiation J. Nucl. Mater Vols. 307 311 (2002) $1107-1111$

[31]P. V. Vladimirov, D. Lizunov, Yu. A. I. Ryazanov, A. Möslang, Damage calculation in fusion ceramics: comparing neutrons and light ions, Journal of Nuclear Materials Vol. 253 (1998) $104-112$

[32]M. Salvador, J. M. Perlado, A. Mattoni, F. Bernardini, L. Colombo, Defect energetic of $\beta$ $\mathrm{SiC}$ using a new tight-binding molecular dynamics model: Journal of Nuclear Materials, Vols. 329 - 333 (2004) 1219 - 1222

[33]R. J. Price, Neutron irradiation-induced voids in $\beta$-silicon carbide: J. Nucl. Mater Vol. 48 (1973) $47-57$
[34]T. Yano, H. Miyazaki, M. Akiyoshi, T. Iseki, XRay diffractometry and high-resolution electron microscopy of neutron-irradiated $\mathrm{SiC}$ to a fluence of $1.9 \times 1027 \mathrm{n} / \mathrm{m} 2$, Journal of Nuclear Materials, 253 (1998) 78-86

[35]E. E. Haller, Isotopically engineered semiconductors, Journal of applied Physics 77 97 (1995) 2857-2878

[36]R. T. Young, J. W. Cleland, R.F. Wood, M. M. Abraham, Radiation damage in neutron transmutation doped silicon: elelctrical property studies, Journal of Applied Physics 49 (9) (1978) 4752-4760

[37]P. G. Baranov, B. Ya. Ber, I. V. Ilyin, A. N. Opnov, E. N. Mokhov, M. V. Muzafarova, M.A. Kaliteevskii, P.S. Kopév, A. K. Kaliteevskii, O. N. Godisov, I. M. Lazebnik, Peculiarities of neutron-transmutation phosphorous doping of 30Si enriched SiC crystals: Electron paramagnetic resonance study, Journal of Applied Physics, 102 (2007) 063713

[38]M. Bockstedte, A. Mattausch, O. Pankratov, Solubility of nitrogen and phosphorus in $4 \mathrm{H}-$ SiC: A theoretical study, Appl. Phys. Lett. Vol. 85 (2004) $58-60$

[39]P. J. Wellmann, Additional pipework opens up transistor applications for $\mathrm{SiC}$, http://compoundsemiconductor.net/articles/maga zine/11/3/3/1 date of access 2007/01/17 (2005)

[40]J.B. Malherbe, J. P. R. de Villiers, I. Cukrowski, O.A. van der Westhuysen, Milestone 5 Fuel Characterization programme, PBMR Doc. 052570 rev A, paragraph 4.5.1 (2008) 120.

[41]I. J van Rooyen, Effects of phosphorous doping and very high temperatures onthe nanostructures of Silicon Carbide and TRISO coated particles. $\mathrm{PhD}$ dissertation, Nelson Mandela Metropolitan University, March 2011

[42]P. A. Demkowicz, J.D. Hunn, R. N. Morris, J. n M. Harp, P. L. Winston, C. A. Baldwin, F . C. Montgomery, Preliminary Results of PostIrradiation Examination of the AGR-1TRISO Fuel Compacts, HTR2012-3-21

[43]H. X. Xiao, Y. Zhang, L. L. Snead, V. Shutthanandan, H. Z. Xue, W. J. Weber, Near surface and bulk behaviour of $\mathrm{Ag}$ in $\mathrm{SiC}, \mathrm{J}$. Nucl. Mater. 420 (2012) 123-130 